\title{
Evaluation of the Influence of each of Melatonin and Chromium against Diabetes-Induced Alteration in the Testis of Albino Rats Using Light and Electron Microscopies
}

\author{
Nabila S. Hassen*, Nadia M.El Roubi and Enayat A. Omara* \\ Pathology Department* National Research Centre \\ And Histology Department- Cairo University
}

\begin{abstract}
Background: Diabetes mellitus is a global disabling and deadly disease found worldwide. Altered testicular structure and function have been observed in diabetic human and animal models of diabetes with impaired reproductive function. The testicular atrophy and infertility were common in untreated or poorly controlled diabetics.

Aim of the work The present study was carried out to compare the protective effect of melatonin and chromium against testicular alterations in alloxan-induced diabetes in albino rats.

Material and Methods: Thirty-five adult male albino rats were used in this study. The animals were divided into two main groups (each five): non diabetic and diabetic rats, the first group was subdivided into 3 sub-groups: normal control, melatonin-treated animals and chromium-treated animals. The second group was subdivided into 3 sub-group ( each five): diabetic, diabetic rats treated with chromium, and diabetic rats treated with melatonin. Diabetes was induced by a single intra-peritoneal injection of alloxan monohydrate in dose of $60 \mathrm{mg} / \mathrm{kg}$ body weight (BW). The experiment was carried for forty-two days. Computer image analysis was used to measure the thickness of the basement membranes of the seminiferous tubules, the perimeter of the seminiferous tubules and the number of Leydig cells.

Results: In diabetic rats the seminiferous tubules showed statistically significant decrease in diameter, irregular outline and deformed shape because there was degeneration and disappearance of germ cells from many tubules. There was significant thickening of the basement membrane of the seminiferous tubules also detected. Ultrastructurally, nuclei of germ cells showed rarefied chromium and separated areas of nuclear envelop. Spermatids showed abnormal condensed nuclear chromatin surrounded by membranes with focal areas of discontinuity together with vacuolation of Sertoli cell cytoplasm. Melatonin and chromium improved the diabetic alteration in the basement membranes, diameter of the seminiferous tubules and the number of Leydig cells but they did not return to the control values. The improvement with melatonin was more than that with chromium.
\end{abstract}

Conclusion: From the present study, it could be concluded that, melatonin and chromium showed a protective effect on histological alterations of the testis of alloxan-induced diabetes in rats.

Keywords: Diabetes, alloxan, testis, melatonin and chromium.

\section{Introduction}

Diabetes mellitus (DM) affects a considerable number of humans and is a serious disease that has metabolic complications that leads to early morbidity and mortality (Feldman, Stevens and Greene, 1997). Colling and Dicarlo (1995) and Sousa Lion et al. (2004) stated that DM is a constellation of anatomical and biochemical abnormalities resulting in disorder of carbohydrate, lipid and protein metabolism. Furthermore, Salahdeen and Alada (2007) added that DM is a genetically determined chronic disorder of carbohydrate metabolism that results in clinical syndrome combining several pathological events into a common clinical picture.

Altered testicular structure and function have been observed in diabetic 
men and animal models of diabetes with impaired reproductive function. The reported testicular abnormalities included suppression of mating behaviour, oligospermia and involution of secondary sex organs which in part reflected depressed levels of serum testosterone. Thus, the testicular atrophy and infertility were common in untreated or poorly-controlled diabetics (Sainio et al., 1997).

Melatonin (N1-acetyl-N2-formyl-5methoxykynuramine) is synthesized mainly by the pineal gland and is suggested to have antioxidant and prophylactic properties (Armagan et al., 2006). Melatonin has several important functions such as circadian rhythm regulation, immune enhancement, sleep induction, seasonal reproductive regulation, and light-dark signal transduction. Melatonin is also an effective free radical scavenger and antioxidant. It has been shown to be highly useful in preventing neural degenerative changes. Several studies reported that melatonin has mild to moderate hypnotic action in animals (Harikesh and Anil, 2007).

The direct effects of melatonin on the male reproductive system and testosterone synthesis from Leydig cells have also been examined in studies on animals. Because melatonin binding sites have been detected in the reproductive system of different species, it seems reasonable to assume that melatonin exert its action through direct interaction with the steroidogenic cells of the reproductive organs (Armagan et al., 2006).

Chromium picolinate, is essential for normal carbohydrate and lipid metabolism (Mertz, 1993). Deficiency of chromium has been implicated as one of the causes of diabetic mellitus. Chromium picolinate was found to improve impaired glucose tolerance and near normalize the lipid metaboloism of sterptozotcine (STZ)-induce type I and II diabetic rats (Shinde and Goyal 2001, 2003). The analysis confirmed that chromium picolinate is effective in improving glycemic control and normalizing lipid levels in people with type 2 diabetes ( Broadhurst et al, 2006 Lombardo, 2007).

The present work was designed to evaluate the protective effect of each of melatonin and chromium against diabetes induced alterations in testis of albino rats using light and electron microscopies.

\section{Material and Methods}

\section{Animals used}

Thirty-five adult male albino rats weighing 200-250 $\mathrm{g}$ were used in this study. All rats were housed at room temperature and allowed free water and fed ad libitum. They were randomly divided into two main groups:

Group I (Control group): It is formed of five rats were received only $10 \%$ saline in amounts similar to those given to alloxan- treated rats.

Group II (Diabetic group): It is formed of 30 rats how were fasted for 48 hours but allowed free access to water. Diabetes was induced by single intraperitoneal injection of alloxan monohydrate in a dose of $60 \mathrm{mg} / \mathrm{kg}$ body weight (BW). Thirty minutes after alloxan administration, food and water were offered to the animals. All the rats showed no abnormality in blood glucose level before alloxan injection. The presence of diabetes was confirmed by estimation of serum glucose level by portable glucose analyzer and using tail blood samples. Blood glucose level was measured before alloxan injection, 10 days after alloxan injection and immediately before sacrifice. In rats, normal glucose level ranges between 50- $135 \mathrm{mg} / 100 \mathrm{ml}$. Rats were considered diabetic when blood glucose level exceeded $200 \mathrm{mg} / 100 \mathrm{ml}$ (Carvalh et al., 2003). The diabetic group was further subdivided into three subgroups:

A. Subgroup (1): diabetic control: 10 diabetic rats received no medication and kept alive for forty-two days (the end of the experiment)

B. Subgroup (2): (Melatonin-treated subgroup): 10 diabetic rats received melatonin daily from the time of development of diabetes until the end of experiment (for forty-two days ).

C. Subgroup (3): (Chromium treated subgroup): 10 diabetic rats received chromium picolinate daily for forty-two days after alloxan injection. 


\section{Drugs used:}

1- Alloxan monohydrate (Sigma chemical company ST. LOUIS) was used in a dose of $60 \mathrm{mg} / \mathrm{kg} \mathrm{BW}$. Alloxan solution was prepared fresh just before use in $0.9 \%$ saline containing $0.02 \mathrm{M}$ sodium citrate ( $\mathrm{pH}$ adjusted to 4-5) (El- Missiry and El-Gind, 2000).

2- Melatonin (Amoun Pharmaceutical IndustriesCO) (APIC) was used orally in a dose of $2.5 \mathrm{mg} / \mathrm{kg} \mathrm{BW}$ (Tan et al., 2000). The drug was dissolved in distilled water. A stock solution was prepared weekly (as the drug is unstable) and stored at $4^{\circ} \mathrm{C}$ (Cavallo and Hassan, 1995).

3- Chromium picolinate (Chromium) produced by Arab Company for Pharmaceuticals and Medicinal Plants (MEPACO). It was supplied in capsule form. Each capsule contains $200 \mathrm{mg}$ chromium picolinate. The capsule was opened, dissolved in $1 \mathrm{ml}$ distilled water.The drug was administered orally using intra-gastric tube in a daily dose of $80 \mathrm{mg} / \mathrm{kg} \mathrm{BW}$ (Cefalu et al., 2002).

The testicular specimens were removed and prepared for both light and electron microscopic examinations.

\section{Light microscopic studies:}

Parts from all specimens were excised and processed for paraffin blocks. Sections were cut at $5 \mu \mathrm{m}$ thickness and stained with:

-Haematoxlin and eosin (Drury and Wallington, 1976).

-PAS (periodic acid Schiff) stain to asses the changes in the polysaccharides (McManus, 1946)

\section{Ultrastructural studies:}

Specimens from testicular tissue of all rats were processed according to the method of Grimaud (1990). Semithin sections "1 $\mu \mathrm{m}$ thickness" were cut by Leica ultramicrotome \& stained with $1 \%$ toluidine blue. Ultrathin sections were prepared and stained with uranyl acetate and lead citrate to be examined under JOEL EM 1005 transmission electron microscope using an accelerated voltage of $60 \mathrm{KV}$.

\section{Morphometric studies:}

By using computer assisted image analysis:

1- The thickness of the basement membranes of the seminiferous tubules was measured using interactive measurements menu in 10 fields. Using the image analyzer (Leica Q win 500) with a magnification of 400 (objective $\times 40$ eyepiece $\mathrm{x} 10$ ).

2- The perimeter of the seminiferous tubules was measured using interactive measurement menu in 10 fields. Using the image analyzer (Leica Q win 500) with a magnification of (objective $\mathrm{x} 40$ eyepiece $\mathrm{x} 10$ ).

3- The number of Leydig cells was counted in 20 interstitial spaces for each case using $\mathrm{x} 400$ (objective $\mathrm{x} 40$-eyepiece $\mathrm{x} 10)$.

\section{Statistical analysis:}

The mean values of the data obtained from the image analyzer were calculated and statistically compared using t- test. The $\mathrm{p}$ value was considered statistically significant if it was <0.05. (Armitage and Berry, 1994).

\section{Results}

Light microscopic examination of H\&E-stained sections of the testis of the control rats revealed normal histological structure of the seminiferous tubules bound by the interstitial tissue (Figs. $1 \& 2$ ).

In diabetic control rats, the seminifreous tubules were apparently smaller in diameter with irregular outline and widening of the interstitial spaces. There were collections of residual bodies in the adluminal compartment of the seminiferous tubules (Fig. 3). The tubules showed vacuolation and distorted appearance. There was separation of the spermatomgenic cells from the basement membrane in many tubules. The interstitial spaces showed focal lymph exudates and congested blood vessels (Fig. 4).

Cell loss and spermatogenic arrest were evident in some tubules (Figs. 4\&5). Degeneration of germ cells was obvious. 
Leydig cells showed proliferation and focal crowding in some areas (Fig. 5).

In melatonin-treated diabetic rats, examination of testicular sections revealed improvement of testicular architecture. Many tubules showed normal spermatogenesis but there was still lymph exudates and congested blood vessels in the interstitial spaces (Fig. 6).

In chromium treated diabetic rats, the seminiferous tubules showed spermatogonia, primary spermatocytes, and few spermatids. Most of the spermatogonia had dark nuclei. There were congested blood vessels in the interstitial spaces (Fig. 7).

In PAS-stained sections of the control group, thin regular basement membranes exhibiting moderate reaction were seen surrounding the seminiferous tubules (Fig. 8).

In diabetic control rats, the basement membranes of the seminiferous tubules were thickened and irregular and exhibited intense reaction surrounding destroyed tubules (Fig. 9). While when these rats were treated with melatonin or chromium the basement membranes of the tubules were almost normal and regular and exhibited strong and moderate reactions, respectively (Figs.10 \&11)

Semithin sections of control testis revealed normal architecture of spermatogenic cells and Sertoli cells inside the seminiferous tubules and normal Leydig cells in the interstitium (Fig. 12).

In diabetic control rats, sections of the testes revealed disorganization and degeneration of germ cells; they were separated from the basement membrane. Sertoli cells exhibited markedly vacuolated cytoplasm. Some spermatids' nuclei showed rupture of their nuclear membranes and chromatin degeneration (Figs. $13 \&$ 14). The interstitial spaces were widened. Leydig cells appeared more numerous with vacuolated cytoplasm. Their nuclei showed margination of chromatin. Tubules with degenerated cells exhibited thickened basement membranes (Figs. 14).

In diabetic rats treated with melatonin, sections of the testes revealed vacuolated cytoplasm of Sertoli cells. Few spermatogenic cells exhibited nuclear damage. Few
Leydig cells showed vacuolated cytoplasm and margination of nuclear chromatin. Some germ cells appeared normal (Fig.15).

In chromium-treated diabetic rats, despite of the intact appearance of some tubules, there was separation of spermatogenic cells from the basement membrane of the seminiferous tubules. There was also interstitial vacuolation in some areas. Some spermatogonia exhibited vacuolation of their cytoplasm with nuclear degeneration. Some primary spermatocytes showed irregular indented nuclear outline. Sertoli cell cytoplasm was rarified. Most of Leydig cells exhibited vacuolated cytoplasm and margination of the nuclear chromatin (Fig. 16).

\section{Ultrastructural results:}

Electron microscopic examination of testicular sections of control rats revealed Sertoli cells that exhibited euchromatin of their nuclei with prominent nucleoli, mitochondria \& sER (Fig.17). Spermatogonia were separated from primary spermatocytes by processes of Sertoli cells (Fig. 18) Spermatids showed marginated mitochondria (Fig. 19). Interstitial cells of Leydig showed euchromatin of their nuclei with prominent nucleoli and normal organelles (Fig. 20).

Examination of the diabetic control subgroup revealed Sertoli cells that had many cytoplasmic vacuoles and lysosomes (Fig. 21). They revealed condensed nuclear chromatin (Fig. 22). Some primary spermatocytes showed clumped peripheral nuclear chromatin with widening of the perinuclear space. They showed vacuolated cytoplasm. Thickening of the basement membrane was also observed (Fig. 22). Spermatids showed condensation and margination of their nuclear chromatin with rupture of nuclear membranes. They possessed vacuolated cytoplasm (Fig. 23). Interstitial cells of Leydig exhibited few but dilated sER, lipid droplets and lysosomes. Their nuclei had marginated condensed chromatin (Fig. 24).

In melatonin-treated diabetic rats, nuclei of spermatogonia and primary spermatocytes were apparently normal with cytoplasmic vacuolation (Fig. 25). Leydig cells showed nuclei with condensed 
marginated chromatin. The sER was scanty and dilated (Fig. 26).

In Chromium-treated diabetic rats, Sertoli cell cytoplasm was rarified (Fig. 27). Spermatogonia and primary spermatocytes showed vacuolated cytoplasm and there was widening of perinuclear space of primary spermatocytes (Fig. 28).

\section{Morphometric results:}

The mean thickness of the basement membrane of the seminiferous tubules in the diabetic control subgroup displayed very highly significant increase $(\mathrm{p}<0.001)$ in comparison with the control group and subgroups 2\&3. Both melatonin-and chromium-treated diabetic rats revealed a very highly significant increase in the thickness of the basement membranes $(p<0.001)$ when compared with the control group but it was significantly less than that induced by diabetes. Chromium-treated diabetic rats showed higher significant increase in comparison with melatonintreated rats ( $\mathrm{p}<0.001)$. (Table $1 \&$ Fig. 29).

As regards the diameter of the seminiferous tubules, subgroups 1,2 and 3 it showed very highly significant decrease $(\mathrm{p}<0.001)$ in comparison with the control group. The least decrease in diameter of the seminiferous tubules was found in melatonin treated diabetic rats. Both melatonin and chromium caused a significant increase in the diameter of the seminiferous tubules in comparison with diabetic control subgroup. The increase in melatonin-treated diabetic rats was significantly more than that shown chromiumtreated subgroup $(\mathrm{p}<0.001)$ (Table 2 and Fig. 30).

Experimentally-induced diabetes caused a highly significant increase $(p<0.001)$ in the number of Leydig cells / interstitial space in comparison with the control group and subgroups 2 and 3. Both subgroups 2 and 3 revealed significantly increased number of Leydig cells $(\mathrm{p}<0.05$ $\& p<0.001$ respectively) in comparison with the control but significantly less than subgroup 1. Melatonin treatment caused significant less increase $(p<0.05)$ in the number of Leydig cells when compared with chromium-treated rats (Table 3 and Fig. 31).

It was clear from the morphometric analysis that both melatonin and chromium improved the diabetic alterations in the basement membranes, diameter of the seminiferous tubules and the number of Leydig cells but they did not return to the control values. The improvement achieved with melatonin was more than that fulfilled with chromium. 


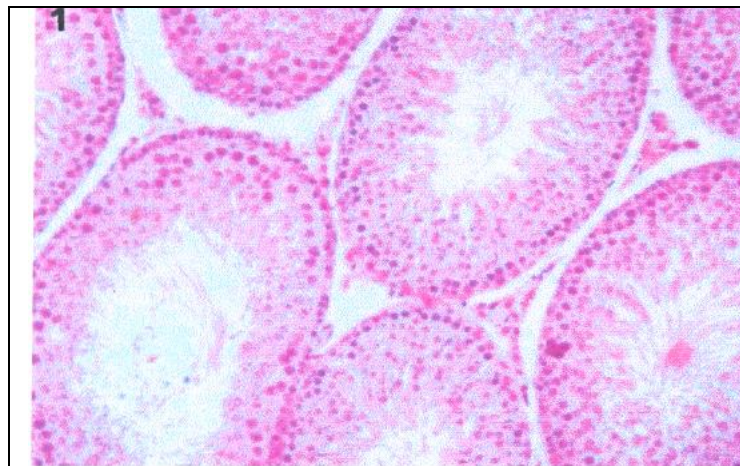

Fig.(1): A photomicrograph of a section in testis of a control rat showing normal architecture of the seminiferous tubules.

(H\& E x 200)

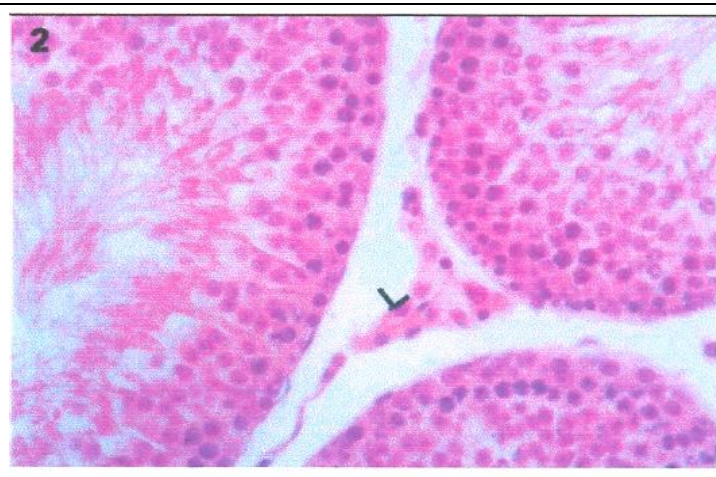

Fig.(2): A higher magnification showing normal appearance of seminiferous tubules \& interstitial cells of Leydig (L).

(H \& E x 400)

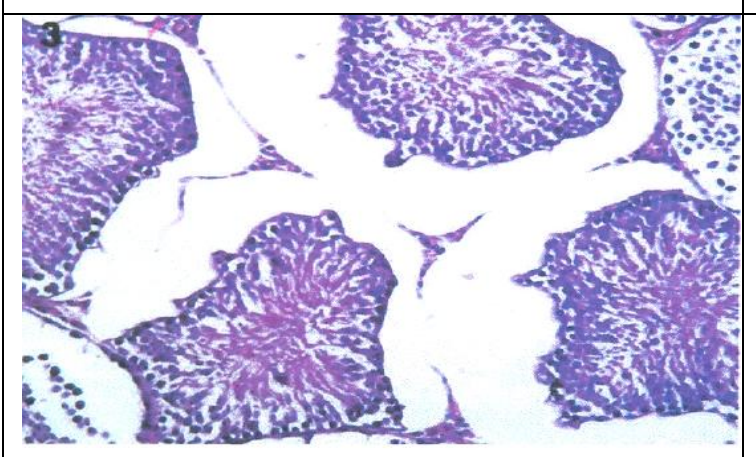

Fig.(3): A photomicrograph of a section in testis of a diabetic rat showing seminiferous tubules with apparently smaller diameter and irregular outline and widening of interstitial spaces between them. Note the presence of residual bodies in the adluminal compartment.

(H \& E x 200)

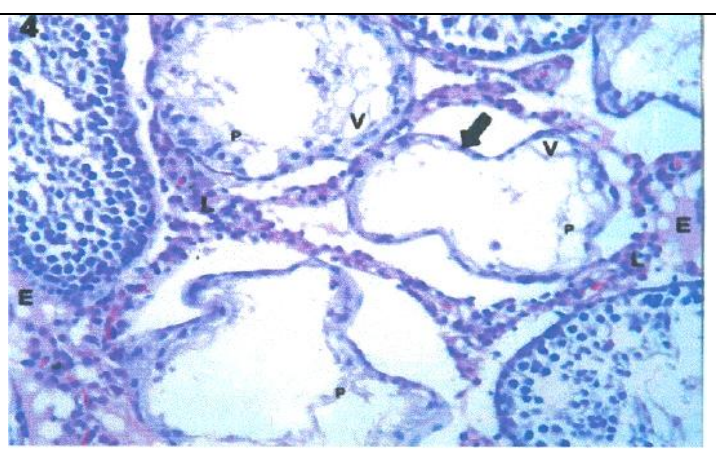

Fig.(4): A photomicrograph of a section in testis of a diabetic rat showing distorted tubular appearance, some of them are devoid of spermatogenic cells (thick arrow) and show vacuolation $(\mathrm{V})$. The interstitial space is widened. There is proliferation of Leydig cells with focal crowding. Interstitial lymphatic ( E) is observed. Note processes of Sertoli cells (P).

(H \& E x 200)

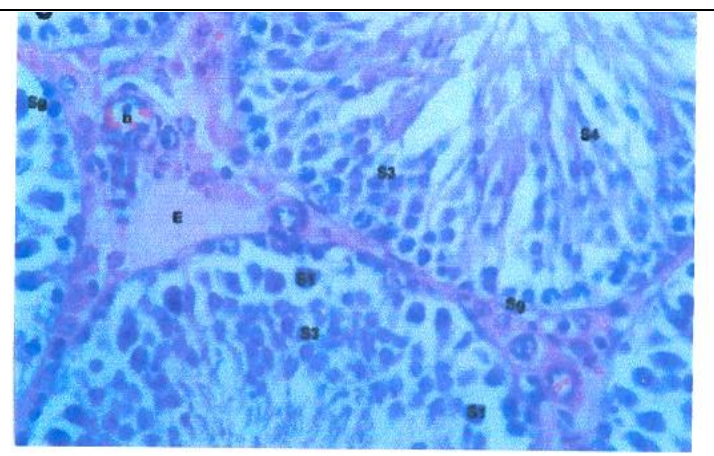

Fig.(6): A photomicrograph of a section in testis of a diabetic rat treated with melatonin showing spermatogonia $(\mathrm{Sg})$, some primary spermatocytes (S1), many spermatids (S3) and some sperms (S4). Note the congested blood vessels (b) and lymphatic exudate $(E)$ in the interstitial space. (H \& E x 400) 


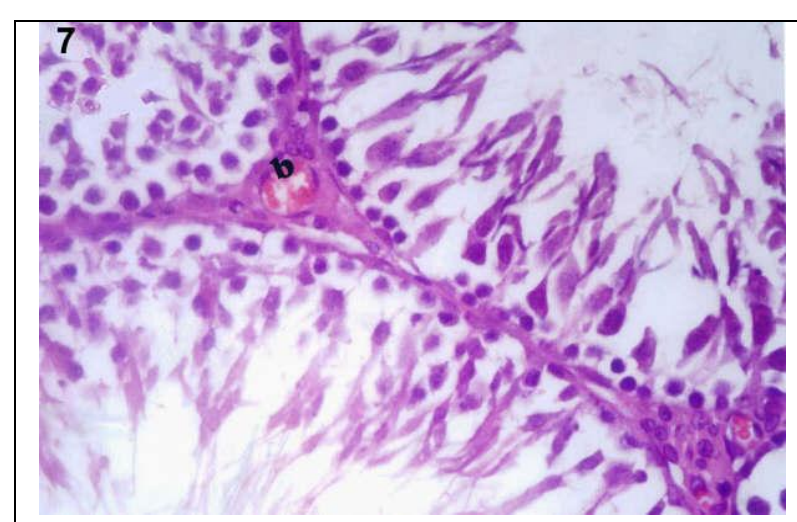

Fig.(7): A photomicrograph of a section in testis of a diabetic rat treated with chromium showing many spermatogenic cells. Note congested blood vessels (b) in the interstitial tissue

(H \& E x 400)

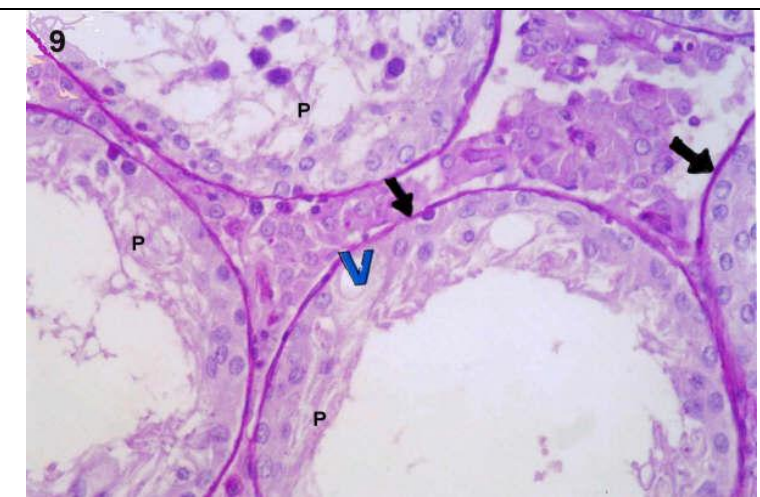

Fig.(9): A photomicrograph of a section in testis of diabetic rat showing thickened basement membranes of the seminiferous tubules exhibiting intense PAS reaction. Note the vacuoles $(\mathrm{V})$ and processes $(\mathrm{P})$ of sertoli cells.

(PAS x400)

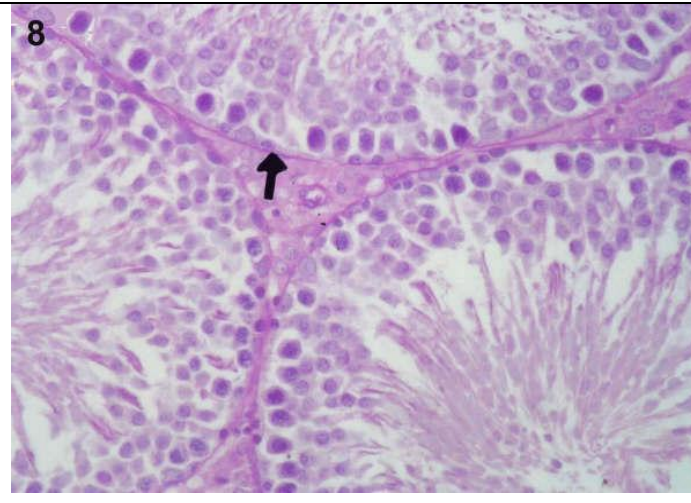

Fig.(8): A photomicrograph of a section in testis of a control rat showing thin regular basement membrane exhibiting moderate PAS reaction surrounding the seminiferous tubules (arrow).

(PAS x 400)

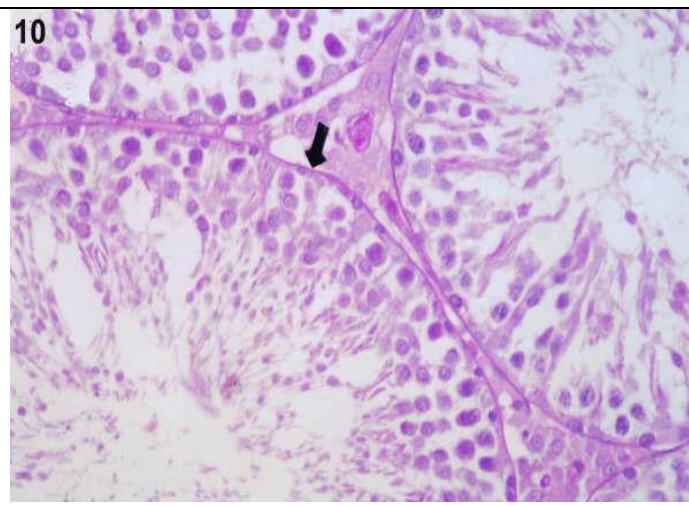

Fig.(10): A photomicrograph of a section in testis of a diabetic treated with melatonin showing apparently thin and regular basement membranes (arrow) exhibiting strong PAS reaction.

(PAS x400)

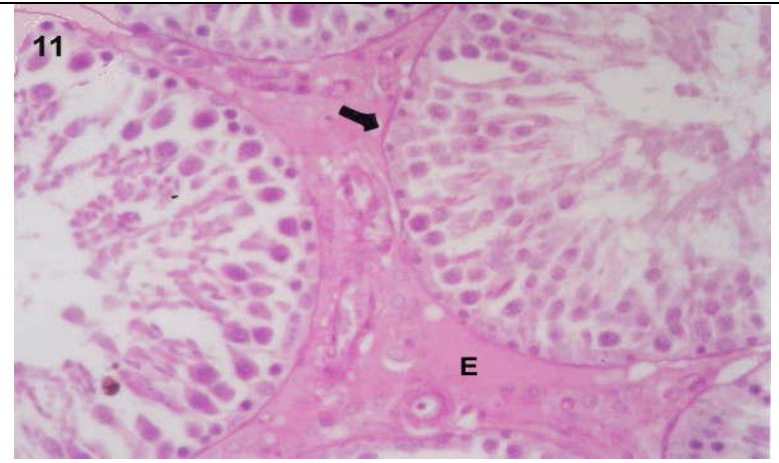

Fig.(11): A photomicrograph of a section in testis of a diabetic rat treated with chromium showing thin basement membranes (arrow) with moderate reaction. Lymphatic exudates (E) are seen. (PAS x 400)

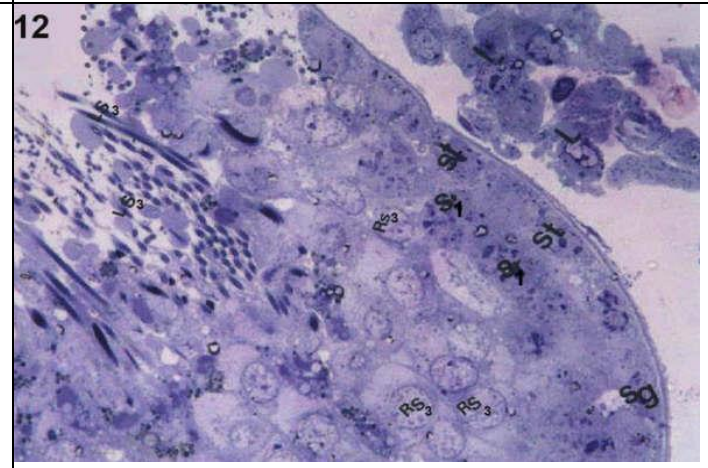

Fig.(12): A photomicrograph of a semithin section in testis of a control rat showing a seminiferous tubule with germ cells in different stages of maturation. Spermatogonia (Sg), primary spermatocytes (S1), round spermtids (RS3), late spermtids (LS3) and seroli cells (St) are seen. Note the presence of leydig cells (L) in the interstitial space. (Toludine blue $\mathrm{x} 1000$ ) 


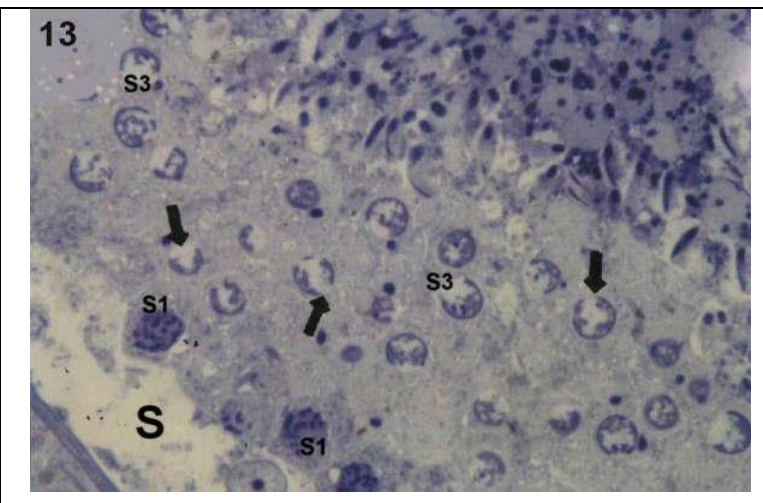

Fig.(13): A photomicrograph of a semithin section in testis of a diabetic rat showing marked separation (S) of spermatogenic cells from the basement membrane of the seminiferous tubule. Primary spermatocytes (S1) are seen to be normal while many spermatids (S3) lost their nuclear outline (arrows). (Toludine blue $\mathrm{x} 400$ )

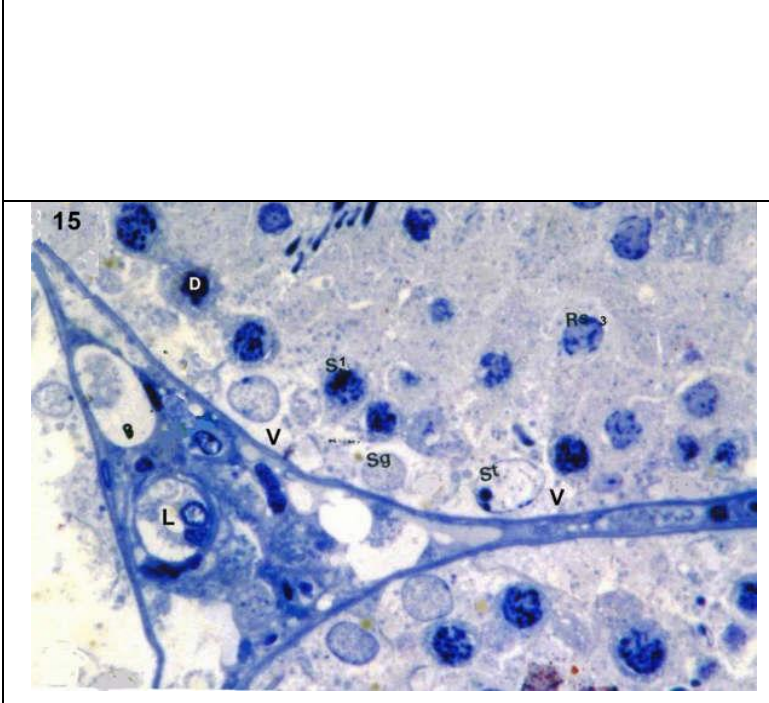

Fig.(15): A photomicrograph of a semithin section in testis of a diabetic rat treated with melatonin showing Sertoli cells (St), spermatogonis (Sg), primary spermatocytes (S1), and spermatids (S3). Note vacuolated cytoplasm (V) of Sertoli cells and degeneration (D) of the nucleus of one primary spermatocyte.

(Toludine blue x1000)

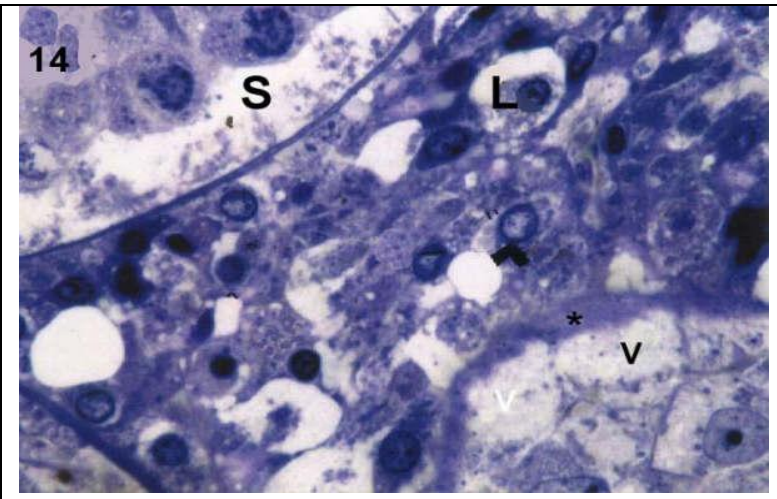

Fig.(14): A photomicrograph of a semithin section in testis of a diabetic rat showing an interstitial space with Leydig cells (L). Some of them show margination of nuclear chromatin (arrow head). There is separation (S) of spermatogenic cells from the basement membrane of the upper left seminiferous tubule. Note the vacuoles (V) that are present in the cytoplasm of the spermatogenic cells in the lower right seminiferous tubule that also has thick (*) basement membrane.

(Toludine blue $\mathrm{x} 1000$ )

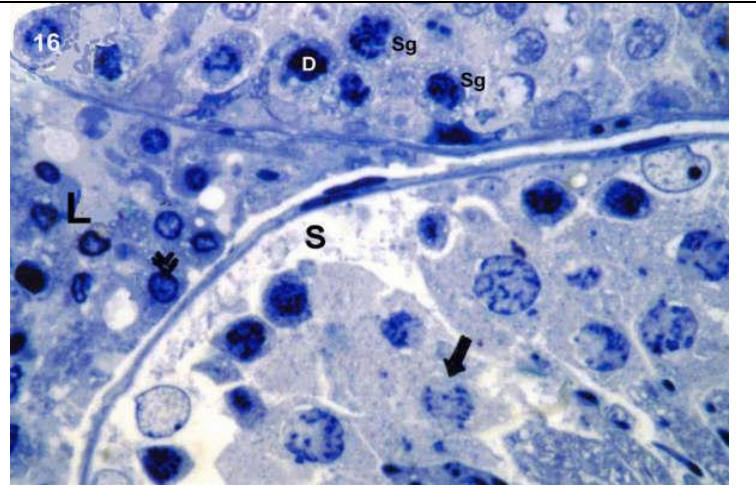

Fig.(16): A photomicrograph of a semithin section in testis of a diabetic rat treated with chromium showing two seminiferous tubules. In the lower one, there is separation $(\mathrm{S})$ of spermatogenic cells from the basement membrane and few primary spermatocytes (arrow) have irregular indented nuclear outline. In the upper one, some spermatogonia $(\mathrm{Sg})$ exhibit vacuolated cytoplasm and one of them exhibits degeneration of its nucleus (D). Leydig cells (L) are showing margination of nuclear chromatin (arrowheads).

(Toludine blue x1000) 


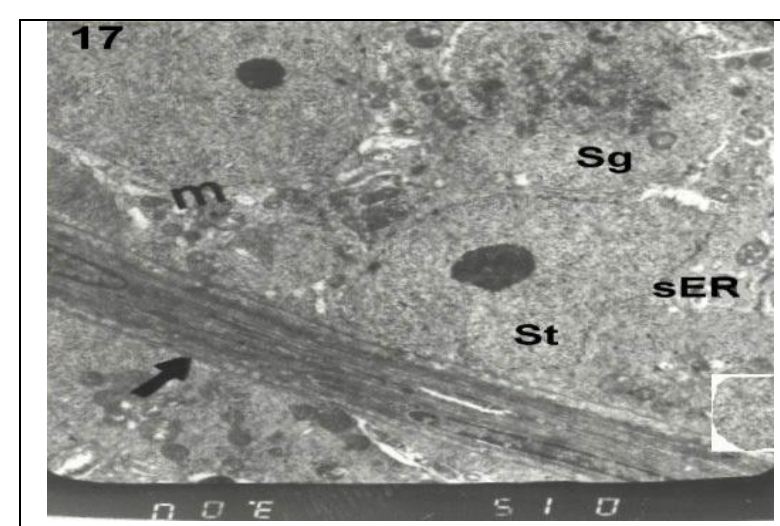

Fig.(17): Electron micrograph of a control rat testis showing the basal portion of Sertoli cell (St) with its pale nucleus and prominent nucleolus resting on the basement membrane (arrow) of the seminiferous tubule. Numerous mitochondria (m), well developed sER are seen.Also, a spermatogonium $(\mathrm{Sg})$ is seen (Original mag x4000)

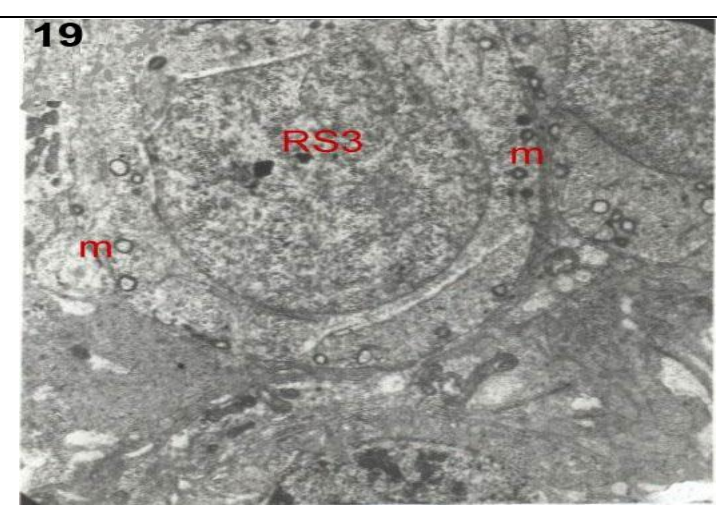

Fig.(19): Electron micrograph of a control rat testis showing early spermatid (RS3) with rows of marginated small mitochondria $(\mathrm{m})$.

x3000)

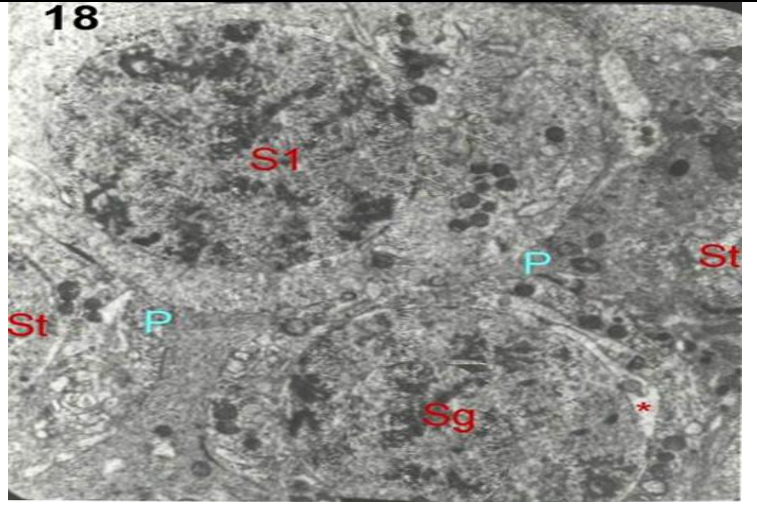

Fig.(18): Electron micrograph of a control rat testis showing parts of two adjacent sertoli cells (St) with tight junction between their processes $(\mathrm{P})$. A pale spermatogonium $(\mathrm{Sg})$ is seen in the basal compartment of the seminiferous tubule and a primary spermatocyte $(\mathrm{S} 1)$ is seen in the adluminal compartment.

(Original mag x6000)

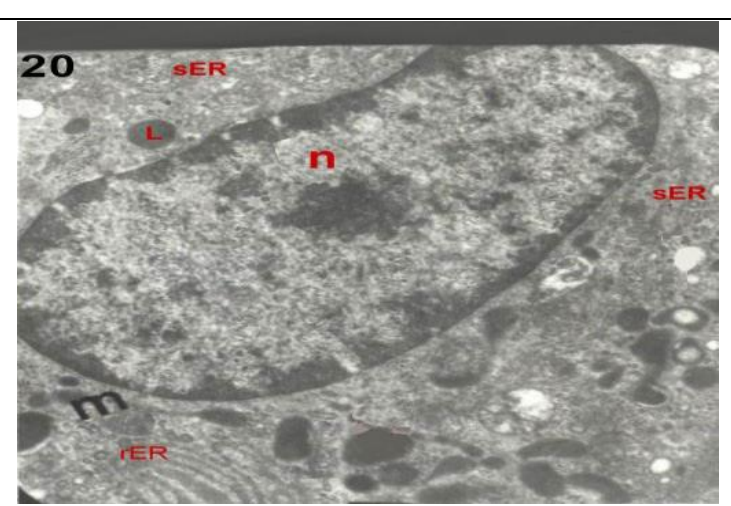

Fig.(20): Electron micrograph of a control rat testis showing interstitial cell of Leydig with normally appearing euchromatic nucleus with prominent nucleolus (n), smooth endoplasmic reticulum (sER), rough endoplasmic reticulum (rER), some mitochondra (m), and lipid droplets (L). (Original mag x8000) 


\section{Evaluation of the Influence of each of Melatonin.........}

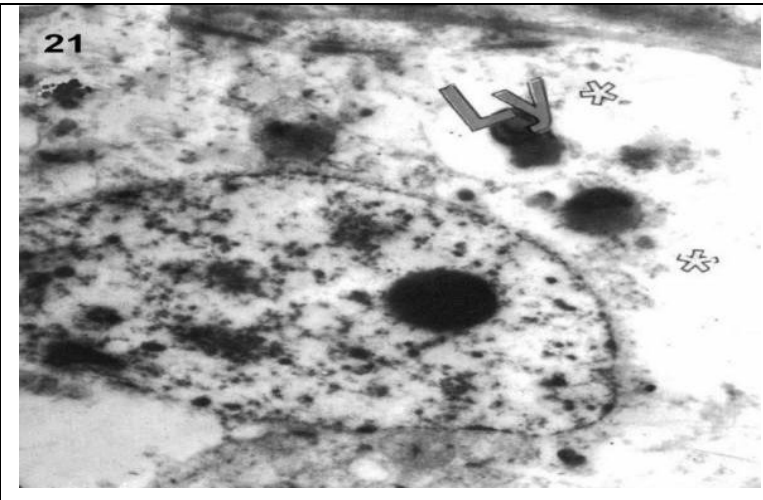

Fig.(21): Electron micrograph of a diabetic rat testis showing vacuolated cytoplasm of sertoli cell (astrix) and many lysosomes (Ly).

(Original mag x4000)

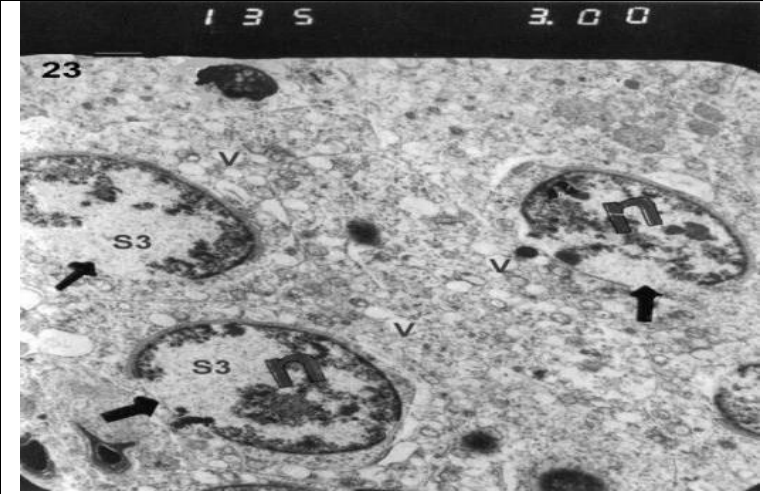

Fig.(23 Electron micrograph $\mathrm{x}$ of a diabetic rat testis showing rounded spermatids (S3) with disrupted nuclear (n) membrane (arrows). Note the vacuoles (v) of their cytoplasm.

(Original mag x3000)

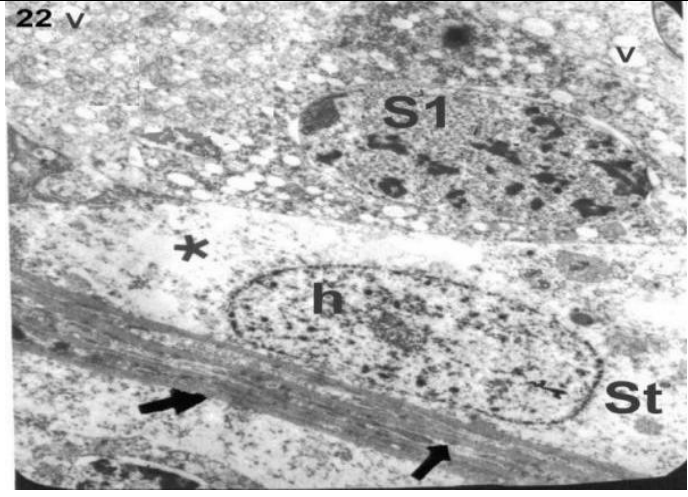

Fig.(22): Electron micrograph of a diabetic rat testis showing the basement membrane (arrow). Sertoli cell $(\mathrm{St})$ shows rarified cytoplasm $(*)$ and appearance of heterochromatin (h) in its nucleus. The primary spermatocyte (S1) cytoplasm shows multiple vacuoles (v) and widening of perinuclear space. (Original mag x3000)

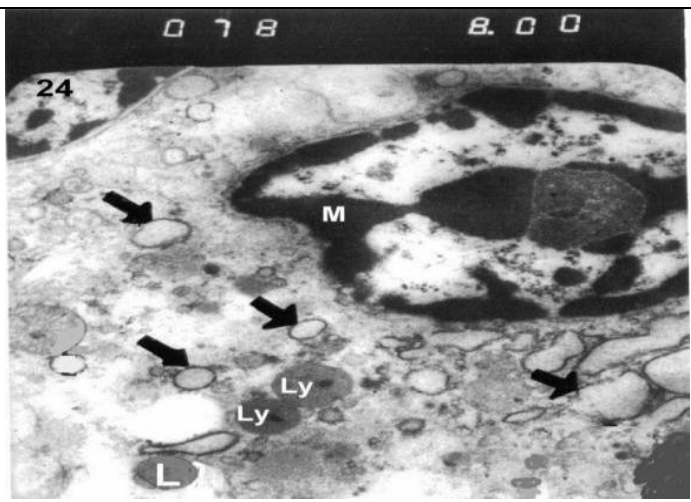

Fig.(24): Electron micrograph of a diabetic rat testis showing Leydig cell. The cytoplasm shows few dilated sER (arrows), lysosomes (Ly) and lipid droplets (L). The nucleus has marginated (M) chromatin.

(Original mag x8000) 


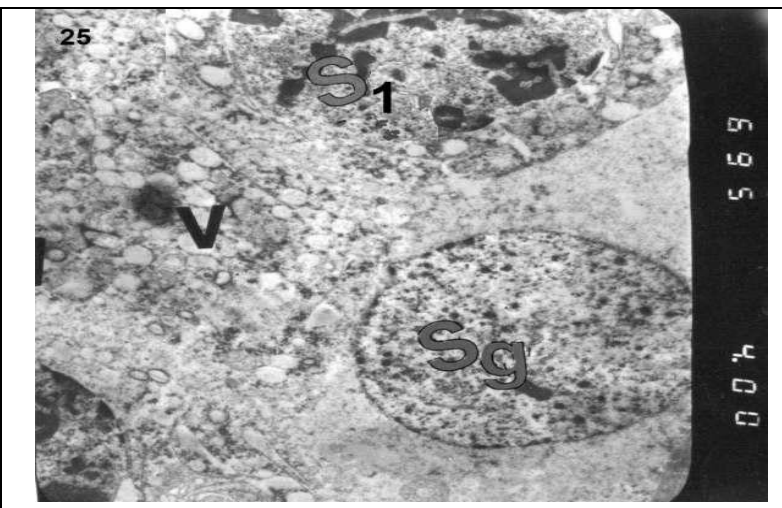

Fig.(25): Electron micrograph of testis of a diabetic rat treated with melatonin showing a spermatogonium (Sg) and primary spermatocyte (S1). Both have vacuolated cytoplasm (v). (Original mag x4000)

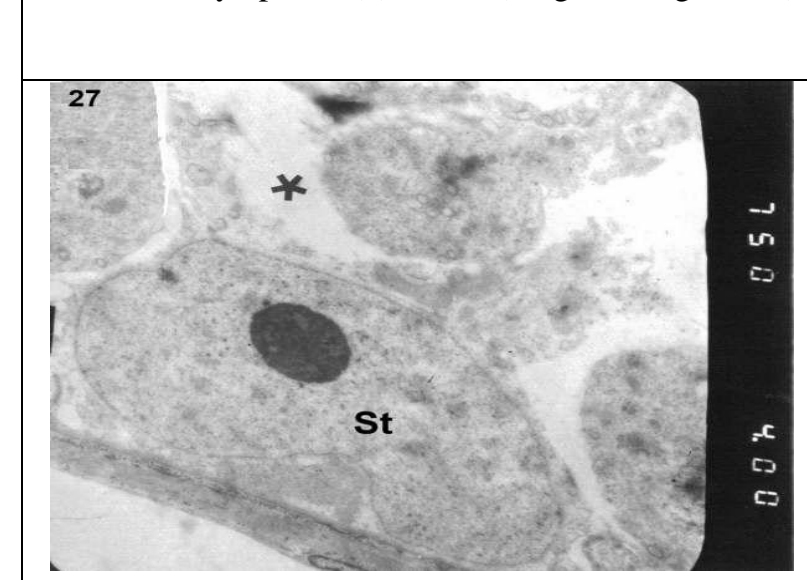

Fig.(27): Electron micrograph of testis of a diabetic rat treated with chromium showing sertoli cell $(\mathrm{St})$ with rarified vacuolated cytoplasm (*).

(Original mag x4000)

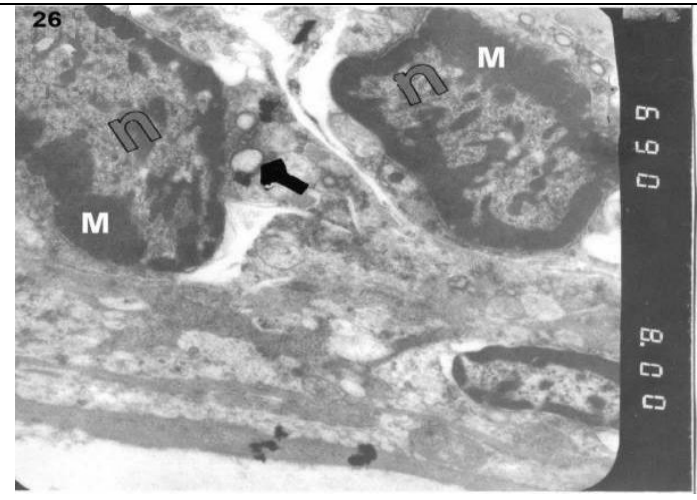

Fig.(26): Electron micrograph of testis of a diabetic rat treated with melatonin showing Leydig cells with condensed marginal (M) chromatin in their nuclei (n) and scanty dilated sER. (Original mag x8000)
Fig.(28): Electron micrograph of testis of a diabetic rat treated with chromium revealing a spermatogonium $(\mathrm{Sg})$ with vacuolated cytoplasm (v). The primary spermacyte (S1) has widening of the perinuclear space $(*) \quad$ (Original mag x 8000)

Table (1): Shows the mean thickness of the basement membrane of seminiferous tubules in different groups \& subgroups.

\begin{tabular}{|c|c|c|c|c|}
\hline Item & control & diabetic control & Melatonin-treated & Chromium-treated \\
\hline Mean & 1.19 & 5.41 & 1.64 & 2.35 \\
\hline Std Dev & 0.18 & 1.67 & 0.37 & 0.71 \\
\hline Std Error & 0.058 & 0.53 & 0.12 & 0.22 \\
\hline $\mathrm{Tt}$ & & & & \\
\hline vs. control & & $-72.89 *$ & $-7.67 *$ & $-19.95^{*}$ \\
\hline vs. diabetes & & & $7.16^{*}$ & $5.85^{*}$ \\
\hline vs. melatonin & & & & $-6.01 *$ \\
\hline
\end{tabular}

$*$ is very highly significant $(\mathrm{p}<0.001)$

vs: versus 
Fig.29: Shows the mean thickness of the basement membrane of seminiferous tubules in the different groups \& subgroups.

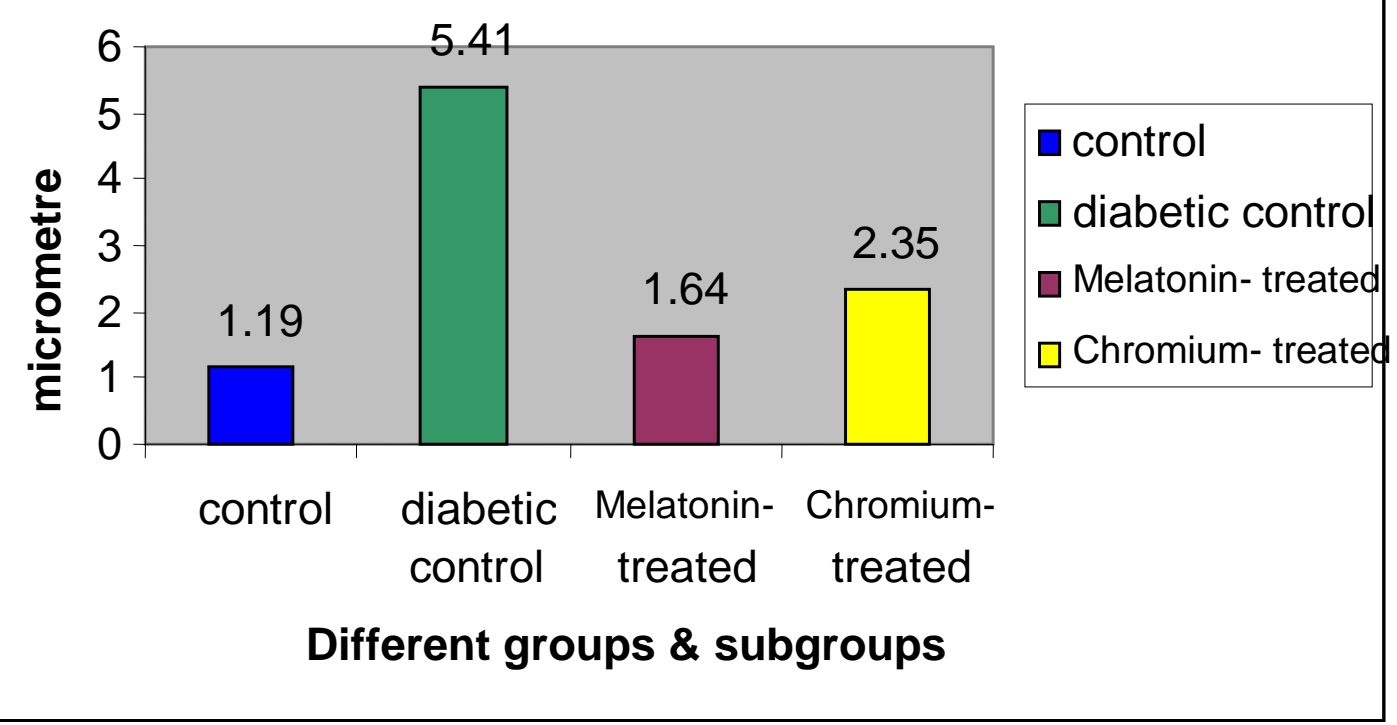

Table 2: Shows the mean diameter of the seminiferous tubules in different groups $\&$ subgroups.

\begin{tabular}{|c|c|c|c|c|}
\hline & control & diabetic control & Melatonin-treated & Chromium- treated \\
\hline Mean & 343.57 & 287.21 & 312.65 & 301.78 \\
\hline Std Dev & 29.96 & 36.77 & 92.55 & 61.13 \\
\hline Std Error & 6.70 & 8.22 & 20.69 & 13.67 \\
\hline Tt & & & & $432.88^{*}$ \\
\hline vs. control & & $76.02^{*}$ & $425.17^{*}$ & $193.11^{*}$ \\
\hline vs. diabetes & & & & $185.10^{*}$ \\
\hline vs. melatonin & & & & $187.40^{*}$ \\
\hline
\end{tabular}

$*$ is very highly significant $(\mathrm{p}<0.001)$ 


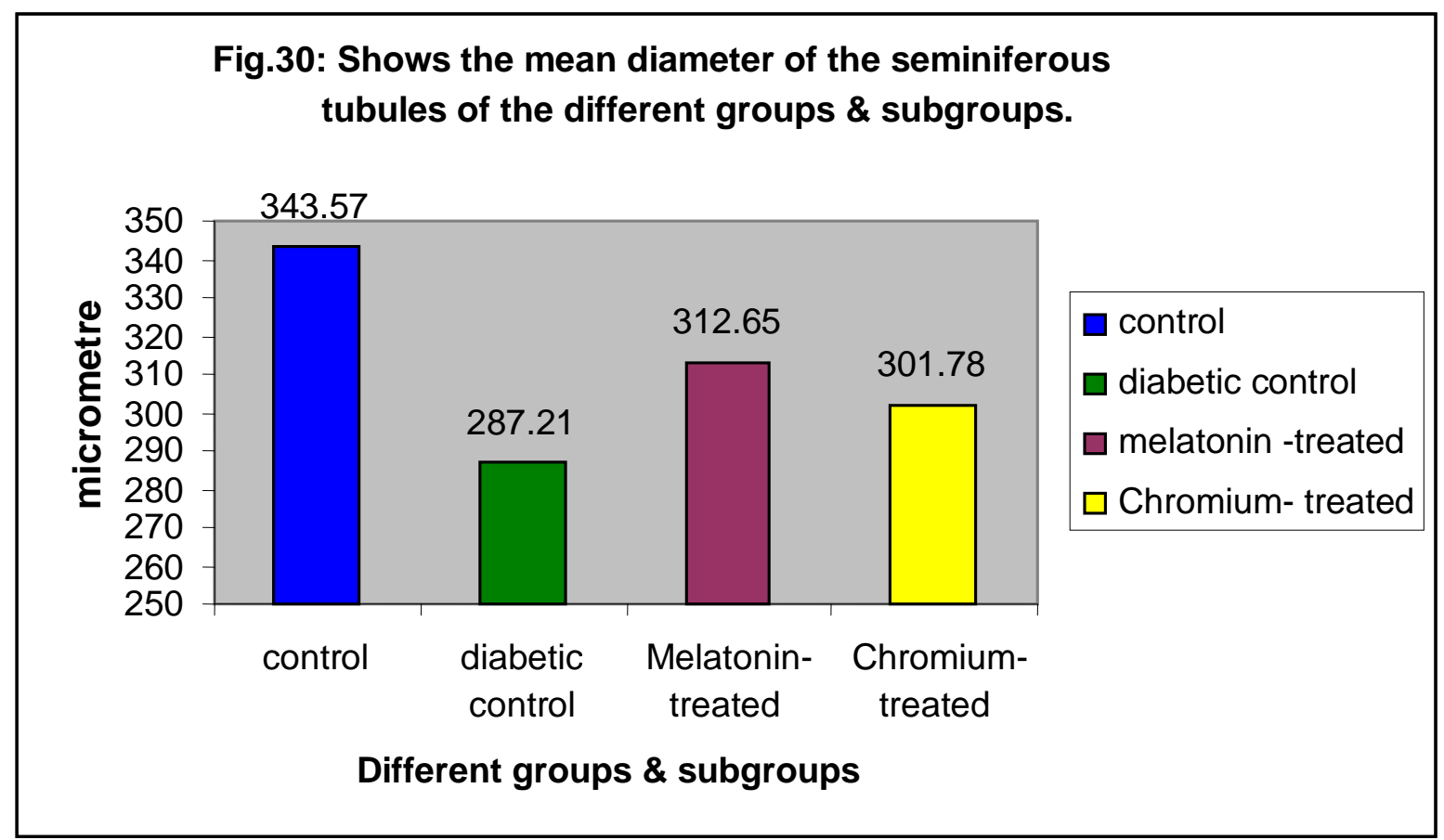

Table 3: Shows the mean no. of Leydig cells/ interstitial space in different groups \& subgroups.

\begin{tabular}{|c|c|c|c|c|}
\hline & control & Diabetic control & Melatonin-treated & Chromium-treated \\
\hline Mean & 2 & 7.7 & 2.8 & 4 \\
\hline Std Dev & 1.03 & 3.07 & 1.23 & 1.94 \\
\hline Std Error & 0.33 & 0.97 & 0.39 & 0.61 \\
\hline Tt & & & & $-5.76^{*}$ \\
\hline vs control & & $-16.56^{*}$ & $-2.30^{*}$ & $4.19^{*}$ \\
\cline { 1 - 3 } Vs diabetics & & $5.20^{*}$ & $-2.71^{\circ}$ \\
\cline { 1 - 3 } Vs melatonin & & & & \\
\cline { 3 - 5 } & & & & \\
\hline
\end{tabular}

$*$ is very highly significant $(\mathrm{p}<0.001)$

is significant $(\mathrm{p}<0.05)$

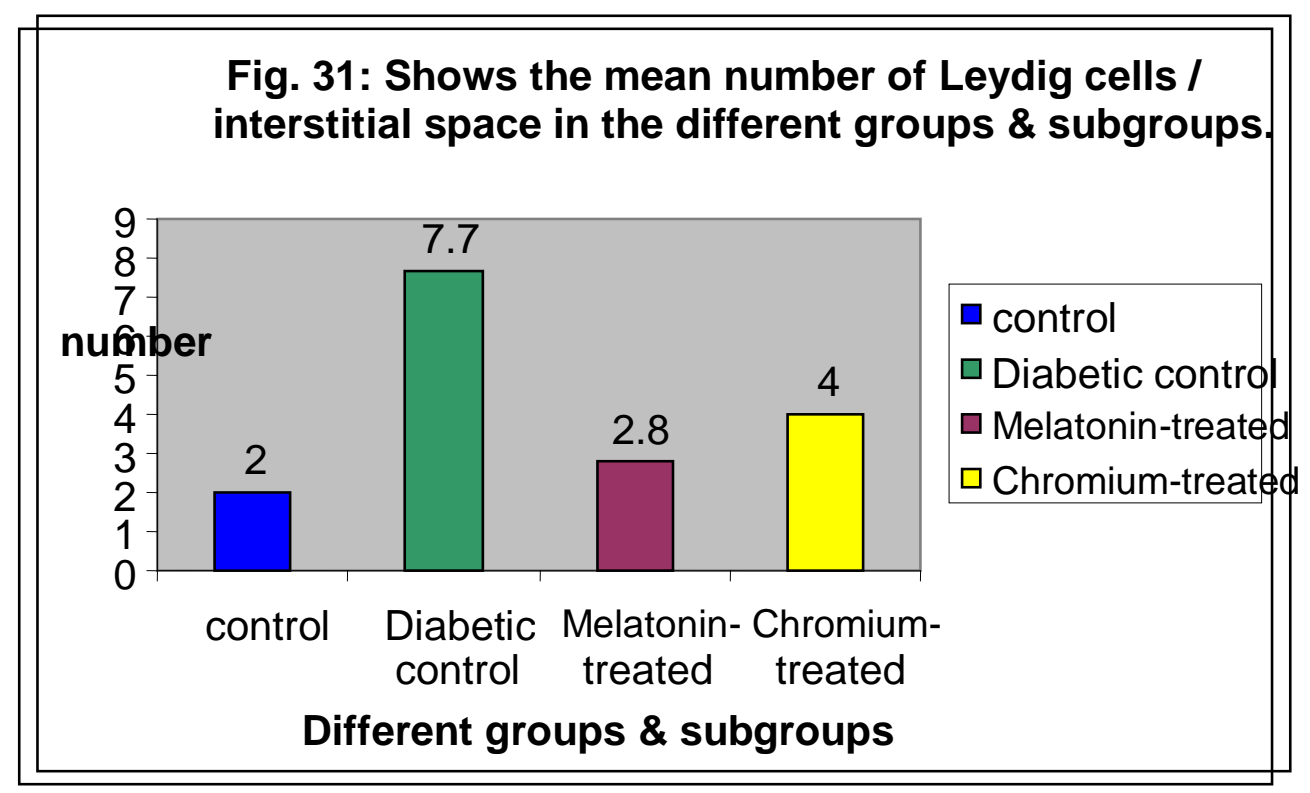




\section{Discussion}

Diabetes mellitus is one of the most common chronic diseases affecting millions of people worldwide. The worldwide prevalence of diabetes is expected to double between 1994 and 2010 to more than 240 million people. Diabetes is a disabling, deadly disease (Searls et al., 2004). The excessive relative risk for death among people with the disease is about twice that of people without. Fortunately, diabetes is often preventable and controllable in many cases (Khan and Safdar, 2003). Alterations in gonadal function including reduced fertility have been described in diabetic men and animal models of diabetes (Altay et al., 2003).

Melatonin is an effective and potent endogenous free radical scavenger and antioxidant. Trivalent chromium is an essential nutrient naturally occurring in all living matter. It is required for protein, glucose and lipid metabolism. The present study was carried out to compare the protective effect of each of melatonin and chromium against testicular alterations in alloxan-induced diabetes in albino rats.

In the present work, structural testicular alterations in diabetic rats werestatistically significant-smaller in diameter; they had irregular outline and deformed shape and displayed degeneration and disappearance of germ cells from many tubules. Using PAS stain, there was statistically significant thickening of the basement membrane of the seminiferous tubules. Ultrastructurally, nuclei of germ cells showed rarified chromatin and separated areas of nuclear envelope. The spermatids showed abnormal condensed nuclear chromatin surrounded by nuclear envelopes with focal areas of discontinuity. Vacuolation and degeneration of Sertoli cell cytoplasm were obvious. These results coincided with what reported by Murray et al. (1983) and Anderson and Thliveris (1986). On the other hand, Cai et al. (2000) claimed that although altered germ cell morphology was not apparent, Sertoli cell pathology was noticed. The relative position of spermatids is maintained through out the spermatogenesis by the distribution of apical Sertoli cell cytoplasm around periluminal spermatids and by Sertoli cell membrane junctional specialization that firmly anchor more advanced spermatids to the epithelium. Thus, the findings of the present work were consistent with the proposed mechanism of degeneration of apical Sertoli cell cytoplasm by which spermatogenesis was disrupted (Cameron, 1985).

This hypothesis was supported by the findings of Naziroglu (2003) which suggested that Sertoli cell function in vitro is altered by a simulated diabetic condition and further support the impression of Sertoli cell pathology associated with diabetes. Sainio et al. (1997) stated that because of constant hyperglycemia levels, diabetic patients are exposed to high oxidative stress; this is because the production of several reducing sugars is enhanced. The reducing sugars can easily react with lipids and proteins (nonenzymatic glycatin reaction), thus increasing the production of reactive oxygen species (ROS). They concluded that despite upregulated defence mechanisms, oxidative damage could be sufficient to impair testicular functions in diabetes.

In the present work, PAS stain revealed that the basement membranes of the seminiferous tubules were noticeably thickened in diabetic rats. This coincided to what was found by Ziyadeh (1993) who reported that this was due to an apparent increase in the volume of the collagen-rich non-cellular layers of the tubular wall. This was consistently associated with disrupted spermatogenesis in man. $\mathrm{He}$ owed thickening of the basement membrane to be due to a dysfunction of peri-tubular fibroblasts, the origin of collagen in peritubular tissue. Then, it would support the suggestion given by Richardson et al. (1995) that patchy intra-tubular pathology might result from altered access to the seminiferous epithelium of systemic factors essential for maintaining normal spermatogenesis. They suggested that increased amount of extra-cellular material was due to peri-tubular fibroblasts which 
are the source of the voluminous amount of interstitial matrix. Dobashi et al. (2002) suggested that thickening of the basement membrane was due to increased amount of collagen due to its retarded turnover. Orisakwe et al. (2004) believed that a higher degree of carbohydrates of procollagen might lead to greater production of collagen in the basement membrane. The observations were consistent with concept of altered collagen distribution and physiology in diabetes. Richardson et al. (1995) made their opinion on such changes. It was possible that the deleterious effects of diabetes on testicular structure and function resulted from accelerated tissue aging. This is due to thickening of the seminiferous tubular wall, peri-tubular and inter-tubular fibrosis and sclerosis. These degenerative changes were seen in testes from both impotent diabetics and aging men.

The testes of diabetic group showed Leydig cell alteration in the form of depleted dilated sER that was concomitant to what was found by Roberto et al. (1995). The nature of these ultrastructural changes seemed to correlate with evidence of decreased Leydig cell function in diabetic rats and might reflect the involution of cellular compartments such as sER which are involved in steroid hormone production. This coincides with the findings of Cai et al. (2000), who found a significant reduction of plasma testosterone levels reflected in lowered prostate and seminal vesicles weight. Interestingly, Hutson et al. (1983) claimed that reduced exposure of Sertoli cells to testosterone resulted in structural and functional degeneration of this key intra-tubular cell type and subsequently to altered spermatogenesis. Many authors had similar suggestions of precocious testicular aging owing to the diabetic conditions in rats and humans. The present observations would not contradict this hypothesis. The significance of increased lipid droplets in Leydig cells was not clear. It could represent an accumulation of stored cholesterol esters for testosterone synthesis. This caused dysfunction of Leydig cells.

The present study revealed a statistically significant increase in the number of Leydig cells in diabetic rats. This might be due to compensatory hyperplasia of the interstitial cells to support the atrophic tubules and in between these cells are Leydig cells (Wright et al., 1982). On the other hand, Cameron et al. (1990) found no change in the number of Leydig cells in diabetic rats while Albrecht et al. (1991) reported an increase in the number of Leydig cells in men with impaired glucose tolerance and decreased number in diabetics. The controversy of results between the present study and these findings might be due to difference in species, mode of induction of diabetes and/or the duration of illness.

In the present work, melatonin administration for diabetic rats showed preserved testicular architecture to some extent. This coincided with the findings of Tan et al. (2000) who reported that melatonin is a potent endogenous free radical scavenger and broad-spectrum antioxidant. Melatonin has been reported to scavenge hydrogen peroxide, hydroxyl radical and nitric acid.

Moreover, Reiter (1998) explained that regardless of the radicals scavenged, melatonin prevents oxidative damage at the level of cells, tissues, organs and organisms. The antioxidant mechanisms of melatonin seemed different from classical antioxidants such as vitamin $\mathrm{C}$, vitamin $\mathrm{E}$ and glutathione. As electron donors, classical antioxidants undergo redox cycling, thus they have the potential to promote oxidation as well as prevent it. Melatonin, as an electron-rich molecule, may interact with free radicals via an additive reaction to form several stable endproducts which are excreted in the urine. Melatonin does not undergo redox cycling and thus, doesn't promote oxidation as shown under a variety of experimental conditions. From this point Sener et al. (2003) considered melatonin a suicidal or terminal antioxidant that distinguishes it from opportunistic antioxidants. Interestingly, the ability of melatonin to scavenge free radicals is not in a ratio of mole to mole. Indeed, one melatonin molecule scavenges two hydroxyl radicals. Moreover, its secondary and tertiary 
metabolites generated when melatonin interacts with free radicals are considered as effective free radical scavengers. In addition, Reiter (1998) reported that melatonin intake to diabetic-induced rats restored the levels of superoxide dismutase (SOD), (an antioxidant enzyme) and glutathione peroxidase to normal prediabetic levels. At the same time, melatonin seemed to help or to alleviate a diabetesinduced drop in nitric oxide.

In the present study, it was clear that administration of melatonin improved the testicular changes of diabetes. This is in agreement with the results reported by Semerioz et al. (2003), who proved that melatonin administration increased antioxidant enzymes' activity and decreased nitric oxide levels. In addition, it stimulates mRNA levels for increased antioxidative capacity of all antioxidant enzymes. It also inhibits nitric oxide synthase (NOS) which is a pro-oxidative enzyme. Furthermore, it protects the nucleus because of reduction of lipid peroxidation and oxidative damage to nuclear DNA. Montilla et al. (1998) proved that melatonin administration in diabetic rats significantly reduced the percentage of glycosylated hemoglobin and oxidative stress. Both represent the two pathogenic corner-stones for diabetic complications. Fortunately, Dennis et al. (1999) suggested that appropriate melatonin supplementation might potentially provide prophylaxis or therapy for some of these prominent pathologies associated with aging. Since most of testicular diabetic complications were due to testicular aging, this made melatonin administration is superior to many antioxidants used to reduce diabetic complications. In addition, melatonin caused improvement of cellular and subcellular testicular alterations of diabetes because of lowering of blood glucose level either systemically or through increased pancreatic glutathione content (Abdel Wahab and Adb-Allah, 2000).

The present study revealed a statistically significant decrease in the thickness of the basement membrane of the seminiferous tubules in melatonin treated diabetic rats. This coincides with results of Tahan et al. (2004) as they implicated that the increase in collagen deposition was due to activation of fibroblasts by free radicals. They explained that since melatonin is a potent physiological scavenger of hydroxyl radicals, it might be involved in the inhibitory regulation of collagen deposition in the tissues. They concluded that melatonin functions as a potent fibrosuppressant and antioxidant.

In the present study, improvement of testicular structures in chromium-treated diabetic rats coincided with what was detected by Shinde (2004). Chromium is the mineral which forms the core of a special molecule called glucose tolerance factor (GTF). This substance is the necessary co-factor that permits insulin to introduce glucose into cells where it is used for fuel. The rate limiting factor for the manufacture of GTF is the availability of organic chromium. Spicer et al. (1998) stated that the micro-nutritional role of chromium in plants, animals, and man has been noted in relation to the ever-increased consumption of highly refined and processed food from which chromium has been either eliminated or greatly reduced.

Nabila et al. (2002) demonstrated medicinal methods of achieving strict glycemic control. They considered chromium as insulin sensitizer agent. They explained the beneficial effects of chromium supplement on fasting glucose, glucose tolerance, blood lipid, insulin bindings and hypoglycemic blood glucose values and symptoms. It has been shown that chromium supplementation could ameliorate diabetic micro-and macro- angiopathies, the single most important factor predisposing to morbidity and mortality in diabetes. It could thus be concluded that- being naturally occurringchromium would be superior to the thiazolide (other insulin sensitizers) due to simple fact that any manufactured drug might induce simple or troublesome side effects or cross reactions.

Shinde et al. (2004) reported that treatment with chromium significantly improved the impaired glucose tolerance and insulin sensitivity of diabetic rats without any change in basal or glucose stimulated insulin response indicating insulin-sensitizing action of chromium. 
Chromium treatment also improved lipid metabolism. They concluded that chromium exhibited significant anti-diabetic potential in chemically-induced diabetes in rats, the mechanism of which appeared to be potentiation of insulin actions at target tissues leading to improved peripheral insulin sensitivity.

In the present study, chromium supplementation produced to less extent an improvement in the histological alterations of diabetic testis. Rabinovitz et al. (2004) supported this concept. They reported that the diabetic deleterious consequence could be greatly prevented by proper strategies to improve insulin resistance by pharmacologic means or nutritional supplementations. This dietary supplementation with chromium has been proposed as one of such nutritional intervention. They mentioned that a therapy that normalizes the metabolic dysfunctions in diabetes expected to prevent, delay or substantially reduce the severity of these long-term complications improving the quality of life. Thus, in the present work, since the structural changes in the testis resulting from alloxan administration in rats could be attributed to the altered metabolism in diabetes. The improvement in the impaired testicular morphology after treatment with chromium could be attributed to its anti-diabetic action resulting in alleviation of the altered metabolic status of diabetic animals.

\section{Conclusion}

From the present study, it could be concluded that melatonin and chromium were found to exert a protective effect on histological alterations of the testis of alloxan-induced diabetic rats. However, melatonin was more efficient in improving diabetes-induced damage than chromium. Thus, the results suggested that supplementation with melatonin to diabetic patients as adjuvant therapy gives hope to a promising perspective of this product and, together with other biological antioxidant, may have some benefit in controlling diabetic complications.

\section{References}

1. Abd EL Wahab M and Abd- Allah A (2000): Possible protective effect of melatonin and/or desferrioxamine against STZ-induced hyperglycemia in mice. Pharmacol. Res. 41(5):533.

2. Albrecht G, Hahn von Dorsche H (1991): Quntitative histological studies of the gonads of sand-rats during the development of diabetes mellitus. Ant Anz, 173(2):101. (English abstract)

3. Altay B, Cetinkalp S and Heking $\mathbf{L}$ (2003): Streptozotocin induced diabetic effects on spermatogenesis with proliferated cell nuclear antigen immunostaining of adult testis. Fertility Sterility, 80: 828.

4. Anderson J and Thliveris J (1986): Testicular histology in streptozotocininduced diabetes. Anat. Rec., 214(4):378.

5. Armagan A, Efkan UZ, Yilmaz R, Sozupek S, Oksay $T$ and Ozcelik N. Asian J Androl. ( 2006): Effect of melatonine on lipid peroxidation and antioxidant enzymes in streptozoticin-induced diabetic rat testis. Asian. J. Andrology. 8(5) 595600.

6. Armitage $P$ and Berry $G$ (1994): Statistical Methods in Medical Research. third edition, Blackwell Scientific Publications, London, p. 40.

7. Baydas G, Cantan $\mathbf{H}$ and Turkoglu A (2002) : Comparative analysis of the protective effects of melatonin and vitamin $\mathrm{E}$ on streptozocin-induced diabetes mellitus. J. Pineal Res., 32 (4): 225.

8. Brodhurst CL, Dommenico $P$ (2006): Clinical studies on chromium picolinate supplementation in diabetes mellitus, A Review. Diabetes Technol. Ther.. 8(6): 677-687.

9. Cai L, Chen S, Evans T and Deng DX (2000): Apoptotic germ cell death and testicular damage in experimental diabetes: prevention by endothelial antagonism. Urol. Res., 28(5):342.

10. 10.Carvalho E, Carvalho $\mathrm{N}$ and Ferreira $\mathrm{M}$ (2003): Experimental model of induction of diabetes mellitus in rats. Acta Cir. Bras, 18: 370. (English abstract)

11. Cameron D (1985): Interstitial compartment pathology and spermatogenic disruption in testis from impotent diabetic men. Anat Rec., 213:53.

12. Cameron D, Rountree R, Schultz D and Murray T (1990): Sustained hyperglycemia results in testicular dysfunction and 
reduced fertility potential in diabetic rats. Am. J. Physiol., 259: E881.

13. Cavallo A and Hassan M (1995): Stability of melatonin in aqueous solution. J. Pineal Res., 18(2): 90.

14. Cefalu W, Wang Z, Baldor $L$ and Russell J (2002): Oral chromium picolinate improves carbohydrate and lipid metabolism in obese hyperinsulinemic rats. J. Nutrition ;132 (6):1107.

15. Colling HL, and Dicarlo SE. (1995): An educational tool for understanding the cardiovascular changes associated with diabetes. Am. J. Physiol.,14: S4-S31.

16. Dennis D, Rasmussen $\mathbf{R}$, Brian $\mathbf{M}$, Charles W, Wilkinson S and Yellon M (1999): Daily melatonin administration at middle age suppress male rat visceral fat, plasma leptin and plasma insulin to youthful levels. Endocrinology, 140(2): 1009.

17. Dobashi M, Fujisawa M, Yamazaki T and Kamidono $S$ (2002): Distribution of intra-cellular and extra-cellular expression transforming growth factor-beta 1 in human testis and their association with spermatogenesis. Asian. J. Androl. 4(2): 105.

18. Drury $R$ and Wallington $E$ (1976): Carlton's Histology Technique, fourth edition, New York, p. 178.

19. El-Missiry M and El- Gindy (2000): Amelioration of alloxan- induced diabetes and oxidative stress in rats by oil of Eruca sativa seeds. Ann. Nut. Metab., 44(3):97.

20. Feldman, eL, Steven MJ, and Greene DA.(1997): Pathogenesis of diabetic neuropathy. Clinical Neuroscience, 4: 365-370.

21. Grimaud J A (1990): Methods in Cellular Biology, European course of cellular pathology .p.59.

22. Harikesh K,and Anil K. (2007): Protective effect of melatonin on certain behavioral and biochemical alterations induced by sleep-deprivation in mice . India. J. Pharmacol., 39 (1): 48-51.

23. Hutson $\mathbf{J}$, Stocco $\mathbf{G}$ and Wagoner $\mathbf{J}$ (1983): Sertoli cell function in diabetic, insulin treated diabetic and semi-starved rats. Diabetes, 32: 112.

24. Khan A and Safdar M (2003): Role of diet, Nutrients, Spices and natural products in diabetes. Pakistan J. Nutrition, 2 (1):1.

25. Lombardo M (2007): Chromium picolinate shows greater benefits in diabetes care than other forms of chromium. Nutrition, 21.

26. Mahmut A, Mehmet E, Hulya A and Mustafa K (2003): Protective effects of
Melatonin against myocardial injury induced by isoproterenol in rats. J. Pineal Res., 35:75.

27. Mc Manus J F (1946): Histological demonstration of mucin after periodic acid. Nature (London), 158: 202.

28. Mertz W (1993): Chromium in human nutrition; J. Nutr. 123 626-633

29. Montilla $\mathbf{P}$, Vargas $\mathbf{J}$, Munoz $\mathbf{M}$ and Cabrera E (1998): Oxidative stress in diabetic rats induced by STZ : Protective effects of melatonin. J. Pineal Res., 25(2):94.

30. Mukhopadhyay $\mathbf{P}$ and Chowdhury $\mathbf{S}$ (2005): Drug therapy in prediabetes. J. Indian Med. Assoc., 103(11): 603.

31. Murray F, Cameron $\mathbf{D}$ and Orth $\mathbf{J}$ (1983): Gonadal dysfunction in the spontaneously diabetic BB rat. Metabolism: 32(7 Suppl 1):141.

32. Nabila A, Monira A , Abdallah B (2002): Tight glycemic control and modalities in the treatment of diabetic complications. Bulletin of the Kuwait Instite for the Medical Specialization 1:89.

33. Naziroglu M. (2003): Enhanced testicular antioxidant capacity in STZ-induced diabetic rats: preventive role of vitamin $\mathrm{C}$, $\mathrm{E}$ and Selinium. Biol.Trace Element Res., 94 (1): 61.

34. Orisakwe O, Husaini $D$ and Afonne $O$ (2004): Testicular effects of sub-chronic administration of Hibi sabdariffa calyx extract in rats. Reprod Toxicol., 18(2): 295.

35. Paskaloglu k, Sener $\mathbf{G}$ and Ayangolu G (2004): Melatonin treatment protects against diabetes - induced functional and biochemical changes in rat aorta and corpus cavernosum. Eur. J. Pharmacol, 499(3): 345.

36. Rabinovitz H, Friedensohn A, Leibovitz a, Gabay G and Rocas c. (2004) : Effect of chromium supplementation on blood glucose \& lipid levels in type 2 diabetes elderly patients. Int. J. Vitam. Nut. Res., 74(3):178.

37. Reiter R (1998): Oxidative damage in the central nervous system; protection by melatonin. Prog. Neurobiol, 56(3):359.

38. Richardson $\mathbf{L}$, Kleinman $\mathbf{H}$, Dym $\mathbf{M}$ (1995) : The effects of aging on basement membrane in the testis. J. Androl., 16(2):118.

39. Roberto E, Kenji O, Kurohmaru $M$ and Hayashi, (1995): Ultrasructural changes in mouse Leydig cells after Streptozotocin administration. Exp. Animal, 44(1): 71. 
40. Sainio P, Henriksen $k$ and Simell, O (1997): Stage-specific degeneration of germ cells in the seminiferous tubules of non-obese diabetic mice. Int .J. Androl. , 20(4): 243.

41. Salahdeen HM, and Alada AR.( 2007): Cardiovascular response to angiotensin II and captopril in normal and diabetic rats loaded with salt. J. Med. Sci., 7(2): 187194.

42. Searls Y, Smirova I, Fegley B (2004): Exercise attenuates diabetes induced ultrastructural changes in rat cardiac tissue. Medicine Science in (Sports Exercse), 36 (11): 1863.

43. Semerioz A, Onur R, Orhan I, Ogras S (2003): Effects of melatonin on testicular tissue and antioxidant activity in experimentally induced left varicocele. Neuro Endocrinol. Lett., 24:86.

44. Sener G, Sehirli A and Dugler G (2003): Melatonin protects against mercury induced oxidative tissue damage in rats. Pharmacol. Toxicol., 39(6):290.

45. Shinde UA and Goyal RK. (2001): Insulin sensitizing action of chromium in experimental models of diabetes mellitus. J. Pharmacol., 33: 51.

46. Shinde UA and Goyal RK. (2003): Effect of chromium picolinate on histopathological alteration in STZ and neonatal STZ diabetic rats. J. Cell Mol. Med. 7 (3): 322-329.
47. Shinde U, Sharma, G, Dhalla N and Goyal R (2004): Antidiabetic activity and mechanism of action of chromium. Exp. Clin. Endocrinol Diabetes, 112(5): 248.

48. Sousa Lion C de, Diogenes JB, Pereira BA, Gomes RA, Andera M, (2004): Antioxidant activity of Bauhinia forficate extract in alloxan-diabetic rats. Biol. Pharm. Bull. 27(1) 125-127.

49. Spicer M, Stoecker B, Chen T, and Spicer J (1998): Maternal and fetal insulin like growth factor system and embryonic survival during pregnancy in rats: interaction between dietary chromium and diabetes. J. Nutrition, 128:1341.

50. Tahan V, Ozaras R, Canbakan B and Uzun H (2004): Melatonin reduces dimethylnitrosamine induced liver fibrosis in rats. J.Pineal Res., 37(2):78.

51. Tan D, Manchester L, Reiter $\mathbf{R}$ and Calvo J (2000): Significance of melatonin in antioxidative defense system: Reactions and products. Biological signals and receptors. J. Pineal Res., 9: 137.

52. Wright J, Yates A, Sharma H, Shim C, Tigner R, Thibert P (1982): Testicular atrophy in the spontaneously diabetic BB Wistar rat. Am. J. Pathol., 108(1):72.

53. Ziyadeh F (1993): Renal tubular basement membrane and collagen type IV in diabetic man. Kidney Int.,43(1):114-20 


\section{دور الميلاتونين بالمقارنة مع الكروميوم ضد التغيرات التى تحدث في خصية

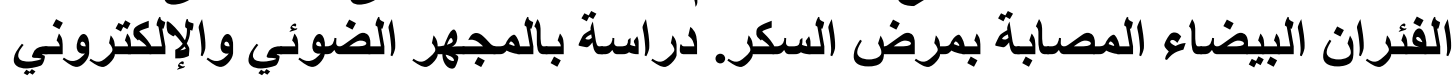

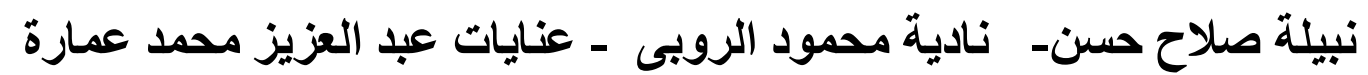

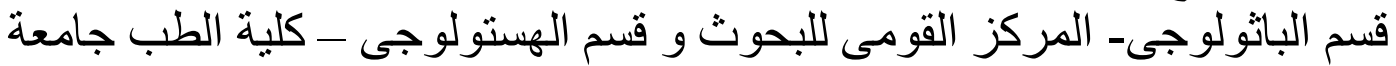

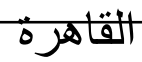

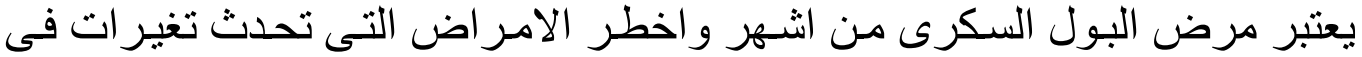

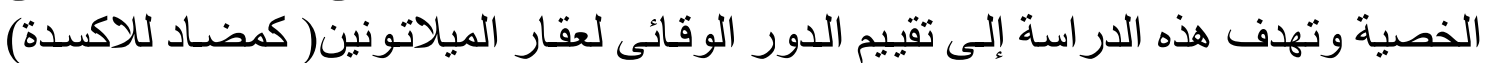

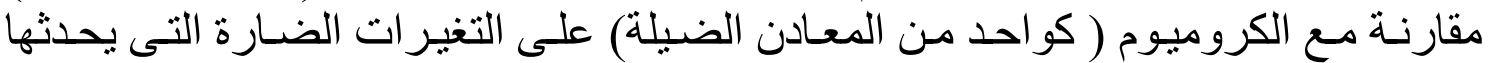

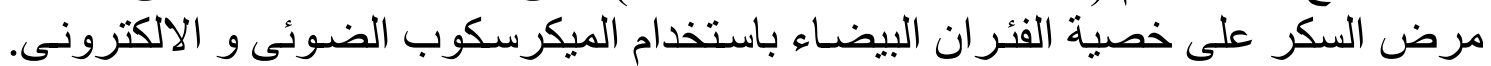

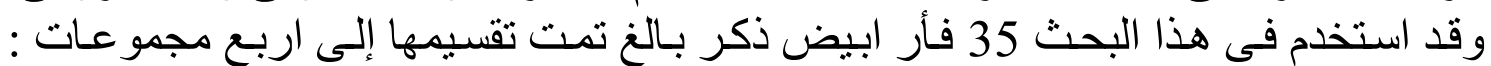

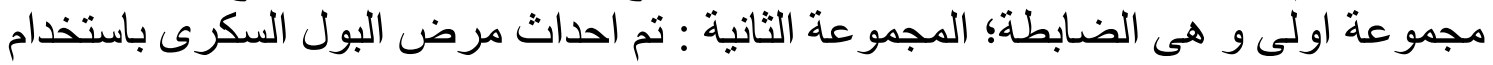

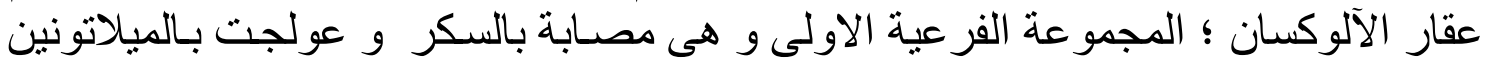

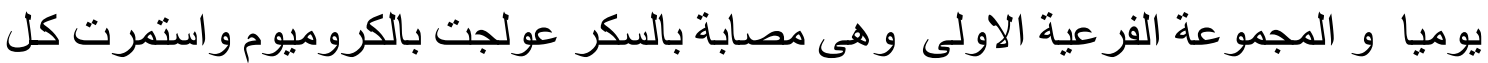

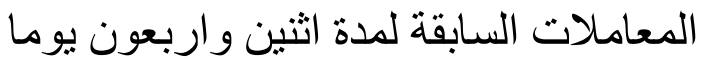

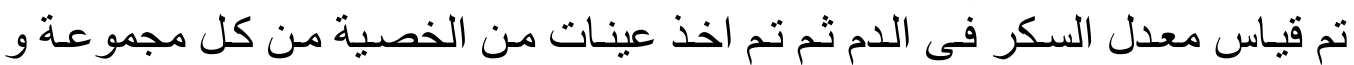

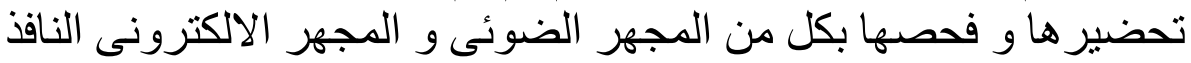

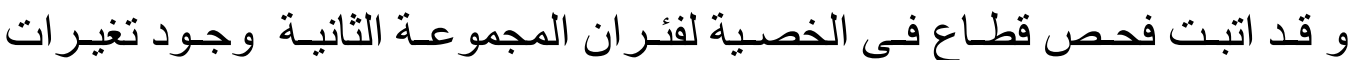

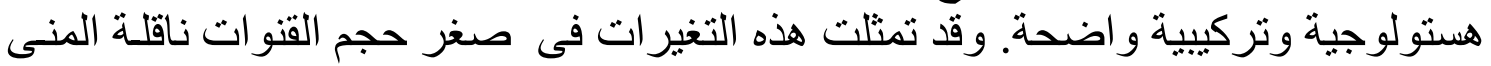

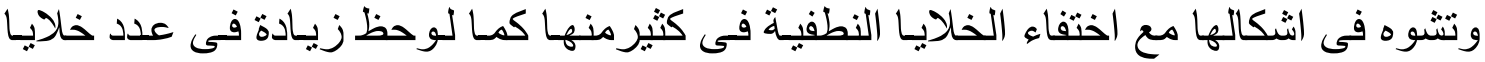

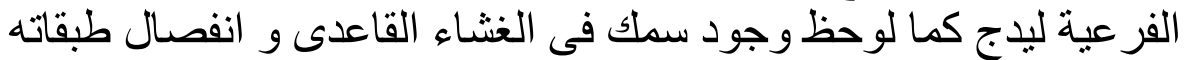

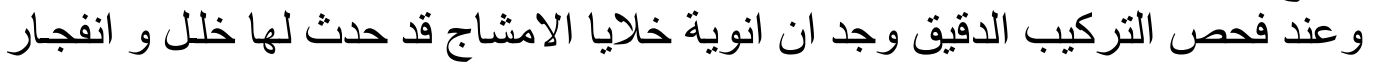

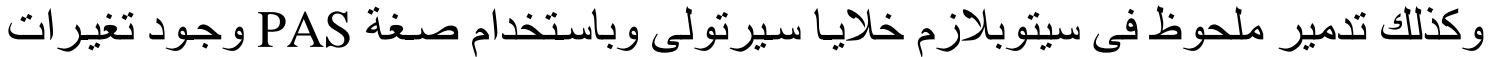
ذات دلالة احصائية فى الخصية

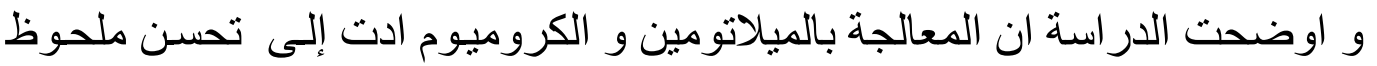

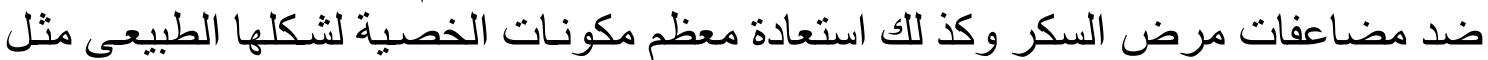

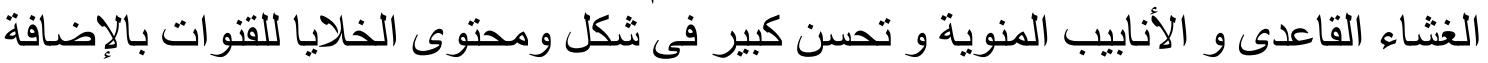

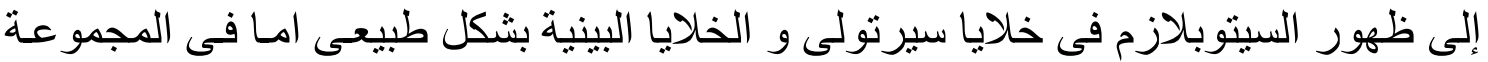

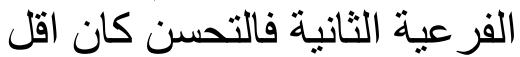

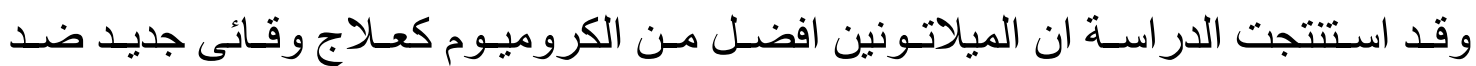
مضاعفات مرض السكر واوصت باستخدامه كعلاج مساعد مع الأدوية الأخرى. 